\title{
Intravitreal injection analysis at the Bascom Palmer Eye Institute: evaluation of clinical indications for the treatment and incidence rates of endophthalmitis
}

\author{
This article was published in the following Dove Press journal: \\ Clinical Ophthalmology \\ 14 May 2010 \\ Number of times this article has been viewed
}

\author{
Ludimila L Cavalcante \\ Milena L Cavalcante \\ Timothy G Murray \\ Michael MVigoda \\ Yolanda Piña \\ Christina L Decatur \\ R Prince Davis \\ Lisa C Olmos \\ Amy C Schefler \\ Michael B Parrott \\ Kyle J Alliman \\ Harry W Flynn \\ Andrew A Moshfeghi \\ Bascom Palmer Eye Institute, \\ Department of Ophthalmology, \\ University of Miami Miller School \\ of Medicine, Miami, FL, USA
}

Correspondence:Timothy G Murray Bascom Palmer Eye Institute, 900 NW I7th Street, Miami, FL 33136, USA

Tel +I 3053266166

Fax + I 30554737 I3

Email tmurray@med.miami.edu
Objective: To report the incidence of endophthalmitis, in addition to its clinical and microbiological aspects, after intravitreal injection of vascular-targeting agents.

Methods: A retrospective review of a consecutive series of 10,142 intravitreal injections of vascular targeting agents (bevacizumab, ranibizumab, triamcinolone acetonide, and preservative-free triamcinolone acetonide) between June 1, 2007 and January 31, 2010, performed by a single service (TGM) at the Bascom Palmer Eye Institute.

Results: One case of clinically-suspected endophthalmitis was identified out of a total of 10,142 injections $(0.009 \%)$, presenting within three days of injection of bevacizumab. The case was culture-positive for Staphylococcus epidermidis. Final visual acuity was 20/40 after pars plana vitrectomy surgery.

Conclusions: In this series, the incidence of culture-positive endophthalmitis after intravitreal injection of vascular agents in an outpatient setting was very low. We believe that following a standardized injection protocol, adherence to sterile techniques and proper patient follow-up are determining factors for low incidence rates.

Keywords: endophthalmitis, intravitreal injections, vascular targeting agents

\section{Introduction}

Intravitreal injections of medications and vitreous substitutes have been performed since 1911. ${ }^{1}$ Their application since then has expanded to encompass the treatment of a great variety of pathologies, with consequent development of new techniques of administration. ${ }^{1}$ Intravitreal use of vascular targeting agents such as triamcinolone acetonide and vascular endothelial growth factor antagonists such as bevacizumab (Avastin ${ }^{\circledR}$; Genentech, South San Francisco, CA) and ranibizumab (Lucentis ${ }^{\circledR}$; Genentech) have gained popularity in the treatment of macular edema of various etiologies, as well as many other posterior segment diseases..$^{2-5}$

Endophthalmitis, although a rare complication of intravitreal injection with these agents, is a serious and clinically relevant concern due to the increase in the frequency and number of injections being performed and the potential loss of vision, which can be permanent in spite of prompt and appropriate management.

A number of protocols have been suggested in order to minimize the rate of infection; however there is no agreement on how to treat and prevent this complication. 


\section{Methods}

The study was approved by the Institutional Review Board of the University of Miami and compliant with the Health Insurance Portability and Accountability Act. Inclusion criteria incorporated all patients injected with vascular targeting agents (triamcinolone acetonide, preservative-free triamcinolone acetonide, bevacizumab, and ranibizumab) in the outpatient clinic of the same service (TGM) from June 1, 2007 until January 31, 2010 at the Bascom Palmer Eye institute, University of Miami Miller School of Medicine.

Injections were recorded in nursing log books and these were later reviewed to assess total number of injections of vascular targeting agents. Patients were also identified through the Anne Bates Leach Eye Hospital electronic medical record for demographic analysis of the data. Clinical indications for injection included: neovascular age-related macular degeneration, choroidal neovascular membranes, radiation retinopathy, diabetic retinopathy, vitreomacular traction, and epiretinal membrane. Culture specimen of the only suspected case was sent to the Microbiology Laboratory of the Anne Bates Leach Eye Hospital for gram stain, fungal, aerobic and anaerobic cultures, and later confirmed by the hospital's Infection Control Committee.

Our analysis was limited to cases where clinical suspicion prompted the request for intraocular cultures or an intravitreal tap with use of intravitreal antibiotics. Signs of infection included marked fibrin, inflammation, pain, and/or significant vision loss presenting within a few days of injection. Cases of post-injection uveitis that were not clinically suspect of infection were excluded.

Standard injection, treatment, and follow-up protocols were followed for all intravitreal injections in this study. Informed consent was obtained and off-label use, in the case of bevacizumab, discussed in detail with the patient before each injection. Preparation before injection was performed by a trained registered nurse following the standard preinjection protocol for the Bascom Palmer Eye Institute. This consisted of instilling 5\% povidone-iodine and $4 \%$ lidocaine drops from single-use dispensers into each conjunctiva and then cleaning the eyelid skin and lashes with $10 \%$ povidoneiodine swabs. A sterile wire lid speculum was inserted and lashes directed away from the eye. Three alternating cycles of povidone-iodine and lidocaine drops were instilled to the inferior fornix and conjunctiva and a lidocaine-soaked cotton tip applicator was applied using pressure to the injection site. Injection was performed with the physician wearing sterile gloves. Each patient received either $4 \mathrm{mg} / 0.1 \mathrm{~mL}$ of triamcinolone acetonide, $4 \mathrm{mg} / 0.1 \mathrm{~mL}$ of preservative-free triamcinolone acetonide, $1.25 \mathrm{mg} / 0.05 \mathrm{~mL}$ of bevacizumab, or $1 \mathrm{mg} / 0.1 \mathrm{~mL}$ of ranibizumab intravitreally through the pars plana in each eye, followed by application of one drop of gentamicin (an aminoglycoside). Patients were instructed to use post-injection topical antibiotics (gentamicin) four times a day for four days; they were not draped for the injection and did not receive antibiotics prior to injection.

All patients were rigorously evaluated before the procedure and followed thereafter with clinical eye examinations, refractive analysis, fundus photos, and ocular coherence tomography. Other adjuvant imaging techniques such as fluorescein angiography and ocular echography were requested on an individual need basis. A standard follow-up protocol was used postinjection and consisted of re-evaluating all patients four to six weeks later during a clinical visit where all the above-mentioned exams were performed for each patient.

\section{Results}

Assessment of all intravitreal injections with vascular targeting agents from June 1, 2007 until January 31, 2010 yielded a total of 10,142 injections of which: 7315 were of bevacizumab (72.12\%), 1195 of triamcinolone acetonide (11.78\%), 981 of ranibizumab $(9.67 \%)$, and 651 of preservative-free triamcinolone acetonide (6.42\%). Figure 1 shows the distribution of the total number of injections for each agent per year of the study. The average number of injections per patient per eye was 3.5, with a median number of 2 and a range of 1 to 34 injections per patient. Median interval between injections was 63 days; however $4.6 \%$ received only one injection during the time span of the study. Figure 2 demonstrates indications for injection based on primary diagnosis and Table 1 shows the baseline characteristics separated by group of intravitreal agent.

Analysis of all injections documented only one reported case of clinically-suspected endophthalmitis, which followed injection with bevacizumab and presented within three days

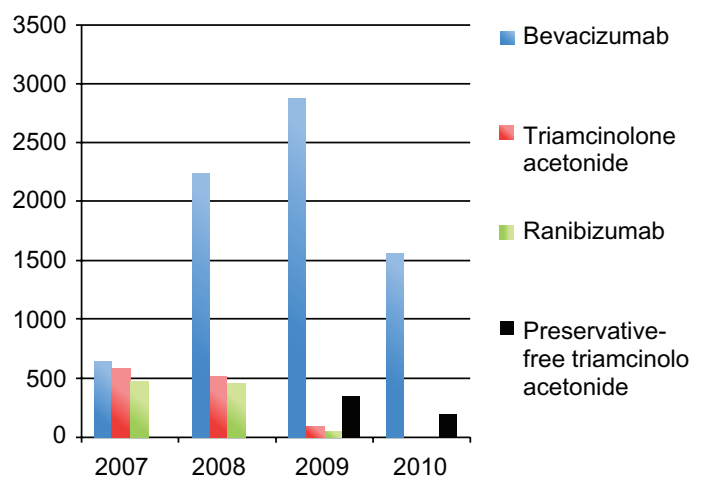

Figure I Distribution of injections of vascular-targeting agents performed per year. 


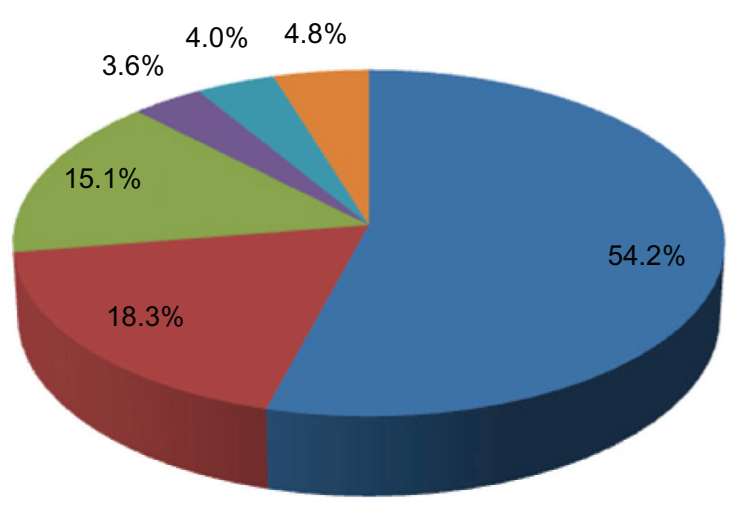

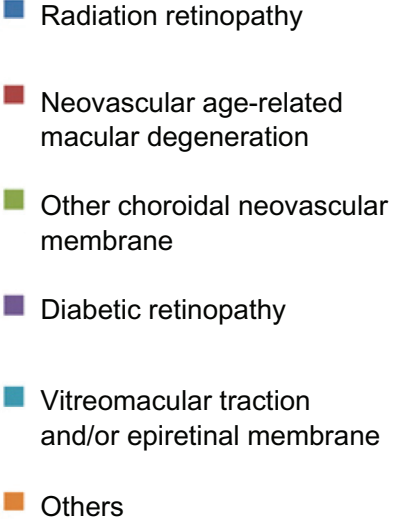

Radiation retinopathy

Neovascular age-related

Other choroidal neovascula

Others

Figure 2 Indications for intravitreal injection based on primary diagnosis.

of the procedure. Intravitreal tap and cultures were performed and the patient received prompt treatment with intravitreal and topical antibiotics.

In this series, the incidence of clinically-suspected and culture-positive endophthalmitis was $0.0098 \%$ for total number of injections, $0.013 \%$ after bevacizumab and $0 \%$ after ranibizumab, triamcinolone acetonide, and preservative-free triamcinoloce acetonide, respectively.

\section{Report of case}

An 88-year-old woman with diagnosis of age-related macular degeneration (AMD), hemorrhagic retinal detachment, and bilateral subretinal neovascular complexes was being treated with vascular endothelial growth factor antagonists (anti-VEGF) at approximately two-month intervals since 10/05/06. She

Table I Baseline characteristics of patients treated with vasculartargeting agents

\begin{tabular}{|c|c|c|c|}
\hline \multirow[t]{2}{*}{ Demographic } & Bevacizumab & Ranibizumab & Triamcinolone \\
\hline & $\begin{array}{l}\text { Group } \\
(n=7315)\end{array}$ & $\begin{array}{l}\text { Group } \\
(n=98 I)\end{array}$ & $\begin{array}{l}\text { Group } \\
(n=1846)\end{array}$ \\
\hline \multicolumn{4}{|l|}{ Age (years) } \\
\hline Median & 67.8 & 79.5 & 67.3 \\
\hline Range & 12.3-88.0 & $21.3-87.1$ & | 5.8-87.7 \\
\hline \multicolumn{4}{|l|}{ Gender } \\
\hline Female & $55.3 \%$ & $54.2 \%$ & $50.5 \%$ \\
\hline Male & $44.7 \%$ & $45.8 \%$ & $49.5 \%$ \\
\hline \multicolumn{4}{|l|}{ Race } \\
\hline Hispanic & $24.9 \%$ & $27.9 \%$ & $22 \%$ \\
\hline \multicolumn{3}{|l|}{ White } & $64.4 \%$ \\
\hline Native & $0.4 \%$ & - & - \\
\hline \multicolumn{4}{|l|}{ American } \\
\hline African & $6.6 \%$ & $0.9 \%$ & $10.2 \%$ \\
\hline \multicolumn{4}{|l|}{ American } \\
\hline Asian & $1.0 \%$ & $0.2 \%$ & $3.4 \%$ \\
\hline Other & $1.3 \%$ & $2.9 \%$ & - \\
\hline
\end{tabular}

presented to the clinic on $06 / 08 / 09$ with visual acuity of 20/30 in her right eye, (the best seeing eye) and intraretinal fluid on optical coherence tomography (OCT), receiving bilateral injections of bevacizumab. Three days later she returned with complaint of decrease in vision, pain, redness, and swelling of her right eye. Upon examination, her visual acuity had declined to 5/200. Slit-lamp examination showed anterior chamber was $3+$ deep with cell and flare, posterior synechiae, and hypopyon were observed (Figure 3). Dilated fundus exam demonstrated presence of marked vitreous debris. B-scan echography confirmed vitreous opacities and membrane formation (Figure 4). An intravitreal tap and injection with ceftazidime $(2.25$ $\mathrm{mg} / 0.1 \mathrm{~mL})$, vancomycin $(1 \mathrm{mg} / 0.1 \mathrm{~mL})$, and dexamethasone $(0.4 \mathrm{mg} / 0.1 \mathrm{~mL})$ was performed, cultures were collected and treatment was followed with topical vancomycin, prednisolone acetate, and cyclopentolate for seven days. Cultures were positive for a quinolone-resistant Staphylococcus epidermidis, sensitive to vancomycin.

Two days later the patient's vision decreased to hand motions. After resolution of endophthalmitis, she had persistent symptomatic vitreous debris, a visually significant cataract, epiretinal membrane, and vitreomacular traction with focal traction retinal detachment. On postinjection day 40, she underwent combined 23-gauge pars plana vitrectomy (PPV), membrane peeling (MP), phacoemulsification, and intraocular lens placement (IOL). At 9-months postoperation her vision recovered and stabilized to 20/30 in that eye. The patient has since undergone five injections of bevacizumab, with no subsequent complications.

\section{Discussion}

In the largest consecutive case review series to date (Timothy Murray, communication with AAM), 34,278 patients from the Bascom Palmer Eye Institute and its satellite clinics 


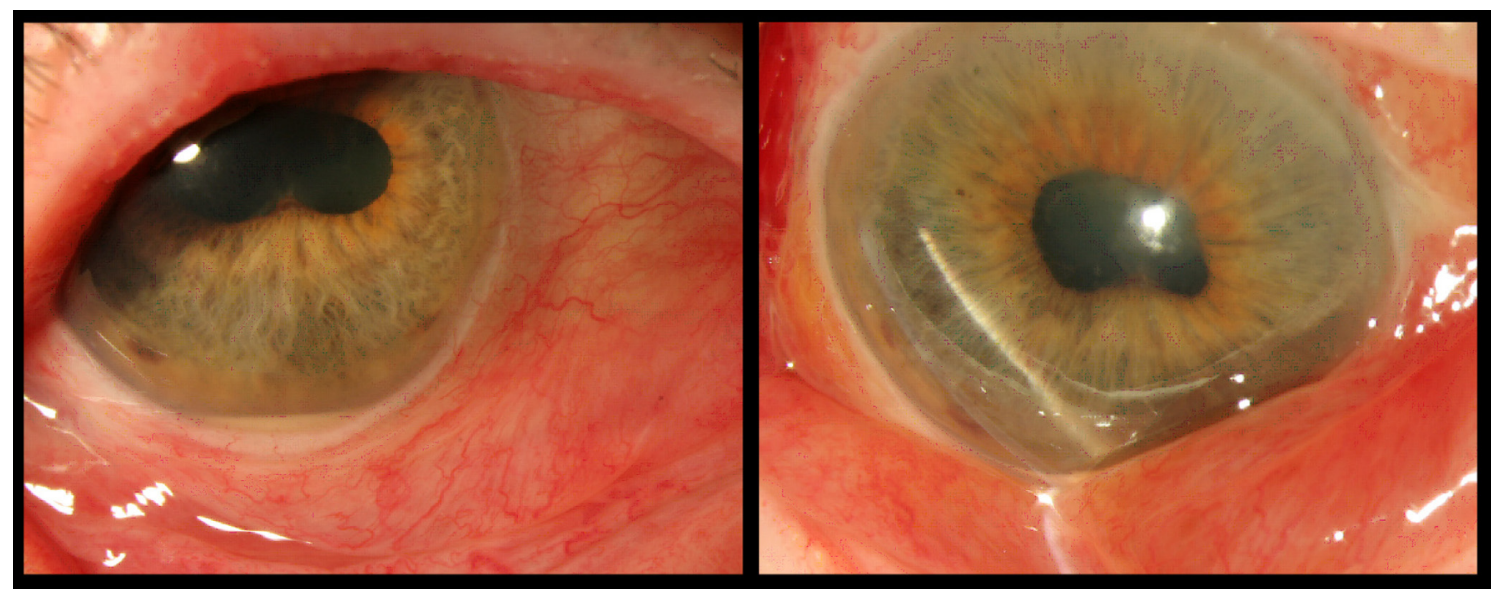

Figure 3 Photograph showing anterior segment of the right eye three days after intravitreal injection with bevacizumab, visual acuity was $5 / 200$. Photo to the right demonstrates conjunctival redness and swelling. Photo to the left displaying hypopyon and scleral redness.

undergoing treatment with intravitreal vascular endothelial growth factor antagonists (bevacizumab, ranibizumab, and pegaptanib) were reviewed between 2005 and 2008, and the per-injection rate of endophthalmitis was found to be $9 / 34,278(0.03 \%)$. Incidence rates of endophthalmitis were $0.023 \%$ after bevacizumab, $0.039 \%$ after ranibizumab injections, and $0 \%$ after pegaptanib. Out of the nine cases reported, five were culture-positive and a larger proportion of streptococcal cases (four out of five) were observed. The authors proposed no explanation for this finding, although isolation of streptococcus species was associated with worse final visual acuity compared to other culture-positive and negative endophthalmitis patients.

The current study analyzes a subset, from a single service (TGM), of the patients described in the study above, in addition to injections of triamcinolone and more current anti-VEGF

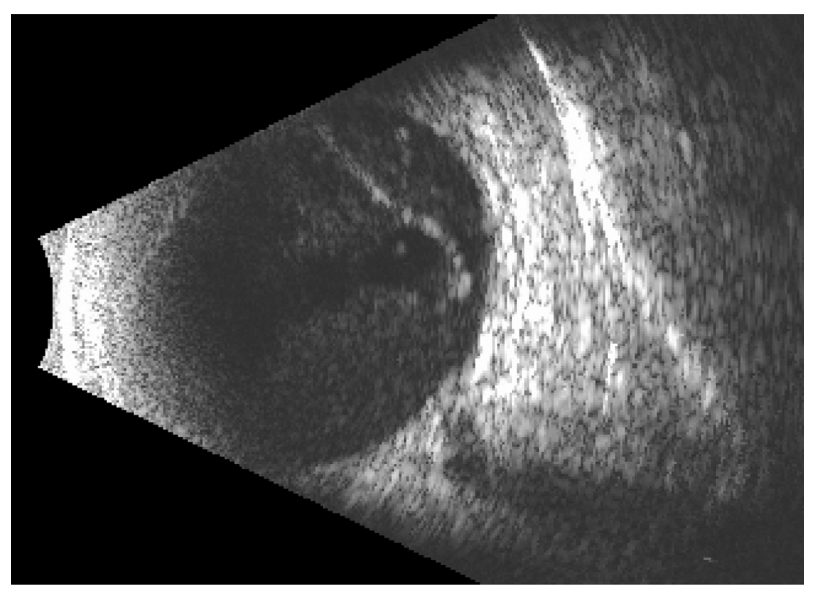

Figure 4 B-scan echography of the right eye showing vitreous opacities with membranes, typical of endophthalmitis. injections. Our incidence of $0.0098 \%$ falls within the range of previous studies and compares favorably to most published series. ${ }^{6}$ Many large studies have reported rates of endophthalmitis following intravitreal injections, ranging from 0.019 to $0.16 \%$ per injection. ${ }^{1,7-11}$ Individual risks for bevacizumab fall in the range of $0.019 \%$ and $0.08 \%$, while ranibizumab lies between $0.02 \%$ and $0.2 \% .^{1,5-8,11,12-14}$ Reported infection rates for triamcinolone acetonide are 0.08 to $0.1 \% .{ }^{15}$ The pathogens most commonly isolated from intravitreal cultures are Staphylococcus epidermidis and coagulase-negative staphylococci. ${ }^{8-10}$

Difficulty remains in clinically differentiating infectious endophthalmitis from noninfectious endophthalmitis, as there is great overlap between these two entities. In infectious endophthalmitis there is typically an anterior chamber cellular reaction with at least some degree of fibrin, which is associated with pain and scleral or conjunctival inflammation. ${ }^{6,16}$

Noninfectious endophthalmitis can present with a hypopyon that may shift with changes in head position, inflammation that is usually only mild and self-limited, and typically there is no pain. These symptoms quickly improve with topical or systemic corticosteroids. ${ }^{6,16}$ Most series report an incidence of $0.5 \%$ to $2.0 \%$ of noninfectious endophthalmitis, which can be attributed in great part to the preservatives in the triamcinolone formulation. ${ }^{2,16}$ In our study, any suspicion of an infectious etiology, generally eyes with marked fibrin, pain or considerable vision loss received standardized treatment with an intravitreal tap and injection, in addition to topical steroids and antibiotics.

Pars plana vitrectomy (PPV) has been employed in the management of endophthalmitis since its introduction in the 1970s and offers some theoretical advantages such as direct removal of the infecting organism, better distribution of antibiotics, 
removal of vitreous membranes, and clearing of vitreal debris, also providing adequate material for intraocular culture. ${ }^{17,18}$ In a series that compared the incidence of endophthalmitis in 6375 patients who underwent 20 -gauge pars plana vitrectomy and 1307 patients who underwent 25-gauge PPV, the rates were $0.03 \%$ and $0.84 \%$, respectively. ${ }^{19}$ Coagulase-negative staphylococcus was the most frequently isolated pathogen, and median time between PPV and endophthalmitis was three days. This report highlights the increasing use of intravitreal adjuvants, such as triamcinolone, as a potential predisposing factor for endophthalmitis after small-gauge PPV. ${ }^{19}$

The limitations of the current study are due to its retrospective nature and reliance on a single service. Its strengths lie on the large number of injections analyzed for the same service and the fact that one hundred percent of the injected patients received standardized evaluation and treatment according to the same protocol and were all seen on a follow-up visit four to six weeks later, so there was no loss to follow-up.

It is difficult to determine whether specific infection precaution measures, particularly the use of drapes, sterile gloves, and prepping of periocular skin have any impact on actual rates of infection. ${ }^{10}$ Suggested standardized injection protocols based on expert consensus agree on the use of a lid speculum, preoperative povidone-iodine, appropriate anesthetic, and avoidance of extensive massage to the eyelids. ${ }^{6,10,20}$ We draw attention to the use of povidone-iodine, which is considered level 2 evidence in expert opinion. Its use has been associated with a reduced number of colonies and a confirmed lower risk of post-injection infections. ${ }^{20}$ In a trial conducted by Speaker et $\mathrm{al}^{21}$ where the application of povidone-iodine to the ocular surface before surgery was compared to the preoperative use of silver solution, a significantly lower incidence of culture-positive endophthalmitis was observed postoperatively in cases where povidone-iodine was utilized prophylactically. This evidence further corroborates the use of povidone-iodine, applied directly to the ocular surface, eyelid margins, and eye lashes before any intravitreous injection. ${ }^{6}$ Another important part of the peri-injection protocol is the lid speculum. It is recommended to avoid needle contact with lids and lashes at all times, but its sterility is not mandatory. ${ }^{6}$

Controversy has revolved around the role of topical antibiotics in the prevention of endophthalmitis, but it is still unclear whether these agents are of any benefit. ${ }^{22}$ In a study reported by Bhavsar et $\mathrm{al}^{9}$ rates of endophthalmitis were not higher when topical antibiotics were not used before, on the day of, or after intravitreal injections of ranibizumab and preservative-free triamcinolone acetonide. Despite this debate, it is customary in our service to use post-injection gentamicin prophylactically, due to evidence showing that topical antibiotics lower the number of bacteria cultured from the conjunctiva and lids. ${ }^{20}$ Our choice of antibiotic was made considering microbial resistance, tolerability, and cost. Gentamicin shows a good sensitivity profile against both gram-positive and negative organisms. There is no apparent increase of coagulase-negative staphylococci resistance to gentamicin, as has previously been observed with fluoroquinolones. ${ }^{20}$

The incidence of culture-positive endophthalmitis after intravitreal injection with vascular targeting agents in the present study is very low. This result compares favorably to rates reported in large clinical trials and other recent publications. We highlight the importance of standardized sterile techniques and close follow-up of patients as major contributing factors to such a low occurrence.

\section{Acknowledgments}

We thank Gabriel Gaidosh and Ditte Hess for their contributions in selecting and formatting the images.

\section{Disclosures}

No conflicts of interest were declared in relation to this paper.

\section{References}

1. Fintak DR, Gaurav KS, Blinder KJ, et al. Incidence of endophthalmitis related to intravitreal injection of bevacizumab and ranibizumab. Retina. 2008;28:1395-1399.

2. Stepien KE, Eaton AM, Jaffe GJ, et al. Increased incidence of sterile endophthalmitis after intravitreal triamcinolone acetonide in spring 2006. Retina. 2009;29:207-213.

3. Rosenfeld PJ, Moshfeghi AA, Puliafito CA. Optical coherence tomography findings after an intravitreal injection of bevacizumab (Avastin) for neovascular age-related macular degeneration. Ophthalmic Surg Lasers Imaging. 2005;36:331-335.

4. Greenberg PB, Martidis A, Rogers AH, Duker JS, Reichel E. Intravitreal triamcinolone for the treatment of macular oedema due to central retinal vein occlusion. Br J Ophthalmol. 2002;86:247-248.

5. Heier JS, Antoszyk AN, Pavan PR, et al. Ranibizumab for treatment of neovascular age-related macular degeneration: a phase I/II multicenter, controlled, multidose study. Ophthalmology. 2006;113: 633-642.

6. Schwartz SG, Flynn HW, Scott IU. Endophthalmitis after intravitreal injections. Expert Opin Pharmacother. 2009;13:2119-2126.

7. Mason JO, Milton FW, Feist RM, et al. Incidence of acute onset endophthalmitis following intravitreal bevacizumab (Avastin) injection. Retina. 2008;28:564-567.

8. Klein KS, Walsh MK, Hassan TS, et al. Endophthalmitis after antiVEGF injections. Ophthalmology. 2009;116:1225.

9. Bhavsar AR, Googe JM, Stockdale CR, et al. Risk of endophthalmitis after intravitreal drug injection when topical antibiotics are not required. Arch Ophthalmology. 2009;127:1581-1583.

10. Diago T, McCannel CA, Bakri SJ, Pulido JS, Edwards AO, Pach JM. Infectious endophthalmitis after intravitral injection of antiangiogenic agents. Retina. 2009;29:601-605. 
11. Gragoudas ES, Adamis AP, Cunningham ET, et al. Pegaptanib for neovascular age-related macular degeneration. $N$ Engl J Med. 2004; 351:2805-2816.

12. Jonas JB, Spandau UH, Rensch F, Von Baltz S, Schlichtenbrede F. Infectious and noninfectious endophthalmitis after intravitreal bevacizumab. J Ocul Pharmacol Ther. 2007;23:240-242.

13. Artunay O, Yuzbasioglu E, Rasier R, Sengül A, Bahcecioglu H. Incidence and management of acute endophthalmitis after intravitreal bevacizumab (Avastin) injection. Eye. 2009;23:2187-2193.

14. Rosenfeld PJ, Brown MD, Heier JS, et al. Ranibizumab for neovascular age-related macular degeneration. $N$ Engl J Med. 2006;355: $1419-1431$.

15. Jonas JB, Kreissing I, Spandau UH, Harder B. Infectious and noninfectious endophthalmitis after intravitreal high-dosage triamcinolone acetonide. Am J Ophthalmol. 2006;141:579-580.

16. Roth DB, Flynn HW. Distinguishing between infectious and noninfectious endophthalmitis after intravitreal triamcinolone injection. Am J Ophthalmol. 2008;146:346-347.
17. Doft BH. The Endophthalmitis Vitrectomy Study. Arch Ophthalmol. 1991;109:487-489.

18. Flynn HW, Scott IU. Legacy of the Vitrectomy Study. Arch Ophthalmol. 2008;126:559-561.

19. Scott IU, Flynn HW, Sundeep D, et al. Endophthalmitis after 25-gauge and 20-gauge pars plana vitrectomy: incidence and outcomes. Retina. 2008;28:138-142.

20. Aiello LP, Brucker AJ, Chang S, Cunningham ET, et al. Evolving guidelines for intravitreal injections. Retina. 2004;S3-S19.

21. Speaker MG, Menikoff JA. Prophylaxis of endophthalmitis with povidone-iodine. Ophthalmology. 1991;98:1769-1775.

22. Scott IU, Flynn HW. The role of topical antibiotic prophylaxis for intravitreal injections. Arch Ophthalmol. 2007;125:974-976.
Clinical Ophthalmology

\section{Publish your work in this journal}

Clinical Ophthalmology is an international, peer-reviewed journal covering all subspecialties within ophthalmology. Key topics include: Optometry; Visual science; Pharmacology and drug therapy in eye diseases; Basic Sciences; Primary and Secondary eye care; Patient Safety and Quality of Care Improvements. This journal is indexed on

\footnotetext{
Submit your manuscript here: http://www.dovepress.com/clinical-ophthalmology-journal
}

\section{Dovepress}

PubMed Central and CAS, and is the official journal of The Society of Clinical Ophthalmology (SCO). The manuscript management system is completely online and includes a very quick and fair peer-review system, which is all easy to use. Visit http://www.dovepress.com/ testimonials.php to read real quotes from published authors. 